\title{
On the challenge of polysemy in contemporary cognitive research: What is conscious and what is unconscious
}

\author{
Vera I. Zabotkina ${ }^{{ }^{*}}$, Elena L. Boyarskaya ${ }^{\mathrm{b}}$ \\ a Russian State University for the Humanities, Moscow, Russia \\ ${ }^{\mathrm{b}}$ Immanuel Kant Baltic Federal University, Kaliningrad, Russia \\ *Corresponding author. E-mail: zabotkina@rggu.ru
}

Background. The problem of polysemy has attracted scholars' attention since antiquity and interest in the phenomenon never lessens. A substantial number of works have been published on the cognitive nature of meaning ambiguity. Despite a new emphasis on the cognitive aspects of polysemy, little has been done towards an integrated approach to the study of this linguistic phenomenon.

Objective and Method. This work's objective was to contribute to an integrated interdisciplinary theory of polysemy. To this end, we explored the cognitive foundation of meaning using empirical and theoretical research methods, but mostly relying on semiotic analysis of texts central to the humanities. In particular, we analyzed the dichotomy of conscious vs. unconscious processing in the acquisition and use of polysemy. For the identification of cognitive patterns of polysemy development in ontogenesis, we used probabilistic conceptual modeling.

Results. The acquisition of meaning is a conscious process: it is a conscious interaction of the speaker with an interlocutor and their common social environment. On the other hand, meanings are unconscious unless a connection between the phonological, acoustic form and the concept is established. Correspondingly, polysemy is conscious when a new meaning is formed in the course of social interaction. However, polysemy, as an inherent language phenomenon, remains unconscious for native speakers, who are unaware of its presence provided they are not involved in some form of intentional language games (pun, zeugma or intended ambiguity).

Conclusion. The present approach to the analysis of meaning ambiguity seems to be a productive endeavor. Further research into polysemy has to be based on a range of additional types of evidence, including those obtained by methods of cognitive neuroscience.

Keywords: cognition, polysemy, meaning acquisition, development, language games, concept, consciousness, unconscious processes 


\section{Introduction}

The problem of polysemy has attracted scholars' attention since antiquity, and the interest in this phenomenon, "the wild world of polysemy ... its apparent semantic chaos" (Pinker, 2007, pp. 112-113), never lessens. Despite a new emphasis on the cognitive aspects of polysemy, little in the way of an integrated approach to the study of this language phenomenon has been done. This work intends to contribute to such an integrated theory. The very term polysemy suggests that one may achieve a much better understanding of what the meaning of a word really is, by the search for answers to the following questions: a) what is the primary meaning of a polysemous word and how is it acquired? b) is there a difference in the mechanisms of acquisition of the primary and secondary word meanings? c) is there a difference in the mechanisms of acquisition of word meanings in adults and children? d) what aspects of polysemy may be conscious, and what unconscious?

Questions about the nature of meaning present fundamental challenges, not only for linguistics, but also, when integrated into an interdisciplinary research paradigm, for philosophy, psychology, and artificial intelligence. There are various types of integrated knowledge that emerge as a result of interaction among the different sciences constituting cognitive science: integrated methodological knowledge, integrated empirical knowledge, and integrated theoretical knowledge. Cognitive semantics is the epitome of this integrative approach, the integration of integrations (Zabotkina, 2016).

It is cognitive semantics, often referred to as conceptual semantics, that allows researchers to break the gridlock in three trends in linguistic research - linguistic determinism, nativism, and radical pragmatism. Linguistic determinism assumes that language and its structure predetermine the nature and character of basic cognitive processes - categorization, perception, etc. - and impose certain limits on the learning process as such. Hence it follows that representatives of different cultures think differently. L. Wittgenstein believed that "the limits of my language mean the limits of my world" (Wittgenstein, 2016). Proponents of nativism think that the human conceptual system, mental processes, and structures are congenital in nature. Radical pragmatics, on the contrary, postulates that the word can mean almost anything depending on the context in which it is used. There is a certain rationale in each of the three schools of thought, but each of them contradicts the other two. The difference between languages - the main argument used by determinists - does not fit into the framework of nativism. Neither does polysemy, the main object of research for radical pragmatists, fit into the mold of determinism. Only cognitive semantics provides a way out of this impasse.

According to the latest research, the semantic system is organized into intricate patterns that seem to be consistent across individuals. Most areas within the semantic system represent information about specific semantic domains, or groups of related concepts. Researchers used a new generative model to create a detailed semantic atlas, the Brain Dictionary, showing which domains are represented in each area of the brain (Huth, de Heer, Griffiths, Theunissen, \& Gallant, 2016). This study convincingly demonstrates that data-driven methods provide a powerful and efficient means for mapping functional representations in the brain. 
However, cognitive linguistics and cognitive semantics rely on both experimental and empirical methods of research, which are of equal value. The skilled intuition of cognitive linguists is useful in studying specific influences of thought and embodied experience. Cognitive linguists need not become experimental psychologists or computer scientists for their work and ideas to be seen as legitimate, with considerable theoretical implications (see Gibbs, 2006, pp. 2-16). This research shows the benefits of empirical methods for the study of meaning.

\section{Method}

The objective of this research is to explore the cognitive foundation of meaning and reflect on the dichotomy of the conscious versus unconscious in the acquisition and use of polysemy. With this objective in mind, we refer to empirical methods of research, introspection, and probabilistic conceptual modelling in the identification of patterns and modalities of conceptual processes underlying polysemy.

We begin with a survey of previously published papers on the theory of meaning viewed from the cognitive perspective, and review several hypotheses concerning the interactions among conceptual system, thought, language, and the multiplicity of meaning. The second stage of the analysis presents empirical research into the unconscious nature of meaning, inner speech, and polysemy. We assume that the meaning of a word is based on the concept it expresses and we argue that meanings remain unconscious until a connection between the phonological, acoustic form and the concept is established. Further on, we analyze the benefits of the integrated approach to the study of polysemy using numerous examples taken from WordNet 3.1, Collins Co-Build Corpus and Dictionary, as well as contextualized samples taken from several corpora - the British National Corpus and CHILDES. The selected language material is used to identify conceptual patterns, or algorithms, of the acquisition of the primary and secondary meanings of polysemous words by children and adults.

\section{Results}

\section{Polysemy and the challenge of meaning}

Cognitive semantics requires an interdisciplinary approach to the study of meaning. One of the most significant works, in our view, is a relatively recent publication by R. Jackendoff's A User's Guide to Thought and Meaning, devoted to the problem of meaning addressed from the perspective of different sciences. Meanings are flexible and adaptive in nature: "The meaning of the word is the concept it expresses.... The meaning of a sentence is the thought it expresses.... Meanings are thoughts expressed by language. ...They are flexible and adaptive" (Jackendoff, 2012, p. 3).

This idea dates back to the works of Lev Vygotsky, who studied the connections among concepts, words, sense, and meaning: "We found the unit that reflects the unity of thinking and speech in the meaning of the word.... That is, we cannot say that word meaning is a phenomenon of either speech or thinking. The word without meaning is not a word, but an empty sound. Meaning is a necessary, constituting feature of the word itself... word meaning is nothing other than a generalization, that is, a concept" (https://www.marxists.org/archive/vygotsky/works/words/ch07.htm). 
In dictionaries the meanings of polysemantic words are organized in a single entry, because lexicographers have found something in common between the meanings, and on this basis, decided to class the word as a polysemous one. In most cases, the conceptual and consequently, semantic, connection between the meanings of polysemous words is not in doubt, but there remains a degree of subjectivity in ascribing meanings to one word. Traditional semantics considers distinguishing polysemy from homonymy as one of its fundamental areas of research. When comparing the structure of polysemous words in bilingual dictionaries, the researcher is faced with an even more difficult task of finding correlations not only between two language systems but, more importantly, between two conceptual systems that appear to be markedly different. One cannot but agree with the poet Marina Tsvetayeva: "Some thoughts are unthinkable in another language" (http:// www.tsvetayeva.com/letters/let_chern).

With this knowledge, what takes place in our mental dictionary ultimately depends upon various hypotheses and assumptions. The hypothesis of unconscious meaning put forward by R. Jackendoff is particularly interesting. According to this researcher, word meanings fulfil two essential functions: a reference function that meanings connect language to the world; and an inference function - that meanings serve as a vehicle of reasoning (Jackendoff, 2012, pp. 47-48).

It is common knowledge that not all concepts can be expressed in words, and not all senses can be conveyed. This is surely an argument in favor of the view that meanings are unconscious. Many languages have expressions such as "this is spinning in my head", "it is on the tip of my tongue", and "this is not what I wanted to say". The human mind clearly identifies the activation of a certain amount of conceptual information connected to a word that does not spring to mind at the right time. There is a feeling that the forgotten word is about to be recalled and will pop up in an instant. But that rarely happens. Everybody has experienced frustration over the inability to recall a word that is so familiar and so common. Consider the excerpt from O. Mandelstam's poem "The Swallow", which poetically describes the situation: "I have forgotten the word I meant to say/and the voiceless thought/ returns to the castle of shadows" (http://www.poetryintranslation.com/PITBR/Russian/Mandelstam).

In these cases, the brain fails to establish a connection between the acoustic form of the word and the concept it expresses. The situation described above often has a continuation - the lost word is recalled much later, as if out of "nowhere", when people are already engaged in another cognitive activity. The brain continues to work on resolving the problem without us being conscious of the task, without us being aware of it. The brain solves the task working in "background" mode.

There is a significant number of concepts that have no names attributed to them. According to S. Pinker, there are concepts that simply refuse to have names: "a concept that everyone wants to express, but for which le mot juste does not yet exist. ... Many gaps in the language simply refused to be filled ... the lout sitting next to you on a train or in an airport lounge who screams into a cell phone the whole time. The disgusting lumps of brown snow that accumulate behind a car wheel... etc." (Pinker, 2008, pp. 304-305). There are no names, aka words, for some fragments of experience, emotions, feelings, or situations, which are familiar to everyone, and strange as it may seem, for objects having no names. Even if the con- 
cept has a name, the entire amount of conceptual information associated with the word is not fully reflected in its meaning.

The acoustic form of a word is activated in three cases: during its acoustic perception, during speech production, or in inner speech. Inner speech has a well-defined form and is observed during different phases of brain activity. Deaf speakers perceive inner speech as a sign language image. According to Jackendoff's hypothesis: "Pronunciation is conscious ... and it is linked to unconscious meaning the thought or concept that the pronunciation expresses" (Jackendoff, 2012, p. 86). Pronunciation results from a physical, acoustic process: to pronounce means "to say, speak or utter something in a certain way" (WordNet). It is impossible to say a word and not to be aware of it, at least of its acoustic form. Sounds belong to the physical world, i.e., the external environment. However, the "acoustic form" also exists in inner speech.

Inner speech is certainly a remarkable phenomenon. L. Vygotsky proposed a theory of inner speech describing its main characteristics. He thought that "in inner speech, we find a predominance of the word's sense over its meaning. A word's sense is the aggregate of all the psychological facts that arise in our consciousness as a result of the word. Sense is a dynamic, fluid, and complex formation which has several zones that vary in their stability. Meaning is only one of these zones, that of the sense that the word acquires in the context of speech" (Vygotsky, 1934, pp. 248-249).

Vygotsky's ideas are of cardinal importance for the cognitive study of polysemy. Of interest is his observation of the dynamics of sense and meaning in different contexts. Vygotsky described inner speech as a complex, dynamic process involving transformation of its predicative, idiomatic structure into syntactically articulated speech intelligible to others. In inner speech, thoughts are verbalized and verbal thoughts take the following course: from the motive that engenders a thought to the shaping of the thought, first in inner speech, then in meanings of words, and finally in words (ibid).

However, it is not clear how to interpret the inner speech that people "utter and hear" in their dreams. Dreams are "whispers of the unconscious", so how can the brain be conscious of pronunciation and the general flow of communication? In his "Psychological Notes", V. Odoevsky, a Russian writer of the $19^{\text {th }}$ Century, describes an amazing creature that he saw in a dream - "a compound of darkness, death, and a minor chord. It is impossible to express it verbally after waking up, but in the dream the creature had a name and the name was clear to me" (Odoevsky, 1975). Will such an acoustic form of the name be considered as perceived, and thus, conscious? Are word meanings still unconscious in the unconscious?

The conceptual scope and meanings of polysemous words are unconscious for native speakers. They do not realize the complexity of the structure of polysemous words, the entire volume of conceptual information encoded by them. The identification of the meaning of a polysemous word occurs so effortlessly that polysemy is perceived as monosemy.

When generating an utterance, the speaker chooses words according to his/ her communicative and pragmatic intention. Polysemy, as it may seem, is a problem for the listener, because he/she must adequately identify the meaning of the polysemous word in a given context. However, native speakers easily identify the 
meaning, and in most cases, are not aware of the presence of polysemy. Both the speaker and the listener perceive the words as monosemous and are unconscious of the presence of polysemy.

The only exceptions are examples of pun and zeugma, in which the speaker uses a deliberately ambiguous word in different meanings to achieve a specific pragmatic effect: "We must all hang together, or assuredly we will all hang separately" (B. Franklin), or "She opened her door and her heart to the orphan" (http://www.wunderland.com/). Our analysis has shown that in such cases, both the speaker and the listener are aware of ambiguity; they are conscious of the multiplicity of meanings.

Speakers are also conscious of polysemy when explaining the meanings of polysemous words, for instance, in academic discourse. The following example shows an intentional, i.e., conscious, cognitive effort to explain the meaning of the adjective "special":

Q: If anyone has any ideas on how to explain the meaning of the word "special", it would be greatly appreciated.

A: Do you mean "special needs", or just "special"? I'd go with "Some people need to receive extra help at school if they have physical or learning difficulties"... dyslexia is a good example? Or if you mean just "special", it's best described as something that's better or greater. "Special" surprise $=\mathrm{a}$ surprise that's better than a run of the mill one. "Special" Agent = a better agent, higher ranking, etc. "Special" Fried Rice $=$ the ultimate in fried rice.

We also argue that meanings are unconscious until a connection between the phonological, acoustic form and the concept is established. However, the acquisition of meaning is a conscious process; it is a conscious interaction of the speaker with another speaker and the external environment. These provisions play an important role in our study of polysemy.

We hold that the acquisition of both primary and secondary meanings of polysemous words most often involves an active cognitive modality, i.e., an interaction with another party to the communication; it is socially and linguistically mediated cognition. The acquisition of a word meaning is an interaction between a significant number of mechanisms - conceptual, social, and linguistic ones, each having a complex nature. Conceptual mechanisms of this conscious process are reflected in the human ability to form concepts, analyze them, and attribute the newly formed concepts to the already existing categories. Social mechanisms manifest themselves in the form of verbal and non-verbal communication, for example, when the speaker can just point to the new signified (the Point-and-Say method).

We have investigated situations (these samples are taken from CHILDES and other sources) when an adult speaker is explaining the meaning of a word to a child. Our research shows that this dialogue follows an almost prototypical scenario:

Child: What is it?

Adult: This is X.

Child: What is X?

Adult: $\mathrm{X}$ is like $\mathrm{Z}$.

Child: $X$ is like $Z$ ? And can Z ......? 
There are numerous examples of such dialogues in various corpora and parents fora containing samples of children's speech (CHILDES et al.). Adult speakers often use analogy, metaphor, comparison, as well as other members of the same conceptual category, helping the child form a new concept. In most cases, children continue to ask questions till they get enough information to form the concept and bind it to its acoustic form:

CHILD: chto takoe derevo?

/what is a tree?/

MOTHER: eto takoe mesto, na kotorom mnogo mnogo listochkov.

/this is a place where many many leaves grow/

MOTHER: I tolstyj stvol s koroj.

/And it has a trunk and bark/

CHILD: chto takoe kra, chto takoe kor?

/ what is ba.., what is ba..k?/

MOTHER: eto kozha u dereva.

/this is the tree's skin/

CHILD: chto takoe malen'kaja berezka?

/ what is a small birch-tree?/

(CHILDES)

In this example, the adult speaker gives the definition of the word tree, describing it as a "place where many, many leaves grow", and then provides additional information about other attributes of the concept - "it has a trunk and bark". This was obviously not enough for the child to form the tree concept. Having been asked for clarification, the adult speaker uses a metaphor, "bark is the tree's skin", or a simile, "bark is like skin", to better explain the meaning. The formation of the conceptual category continues, since the child asks about another member of the same category - a small birch tree.

The formation of conceptual categories and their extension is an ongoing process reflected in language and speech interactions. Consider the following example:

CHILD: a gde Mishkino guljan’e?

/and where is Mishka's walkening?/

MOTHER: na ulice

/out in the street/

CHILD: a gde Mishka ne guljanije?

/and where is Mishka's not walkening?/

CHILD: to niguljanije?

/what is not walkening?/

MOTHER: takogo netu slova.

/there is no such word/

CHILD: chto takoe niguljanije?

/what is unwalkening?/ 
MOTHER: takogo slova net.

/there is no word like this/

CHILD: eto guljanije $+\ldots$

/this is walkening $+\ldots /$

CHILD: eto ...

/this is..../

MOTHER: guljanije eto kogda guljajut.

/walkening is when somebody goes out for a walk/

CHILD: a chto takoe nehoroshee guljan'e?

/and what is bad walkening?/

(CHILDES)

In the example above, not only does the child ask for the clarification of the meaning of guljanije, but she also tries to find out if there is a word opposite in meaning to it - niguljanije. Having heard that there is no such word, the child expresses the idea of negation (Rus. negative particles ne/ni) in another way - by using the adjective nehoroshee (Rus. "not good; bad"). This is a conscious attempt to acquire the meaning and form the dichotomy good vs. bad, which is one of the first oppositions acquired by children.

So, we could argue that the formation of the concept and its attribution to the acoustic form is conscious. Our research has shown that there are certain patterns of cognitive operations that are typical of the acquisition of the primary meaning of a word:

- visual or acoustic input to the echoic or iconic memory;

- assessment of sufficiency/poverty of the stimulus;

- given poverty of the stimulus, initiation of a request for additional information required to overcome the poverty of the input and the stimulus;

- formation of the concept;

- binding the acoustic or visual form to the newly formed concept;

- formation of the meaning;

- storing the meaning in the mental lexicon.

Poverty of the stimulus means both the scarcity of perceptual stimuli (acoustic or visual), as well as the background of the event, the sparseness of the external environment. The following example illustrates the formation of a concept differing from the "correct" or "true" due to the poverty of the stimulus: "I recall my childhood guardian's daughter making me laugh numerous times. She thought my tortoise, Hezakiah, was a hezakiah. I'll bet to this day, she may call a tortoise a hezakiah. I tried to explain to her that it was his name. She understood naming her dolly, but not a reptile" (https://www.buzzfeed.com).

In this example, the poverty of the stimulus - insufficient initial input coupled with the dominance of the situational background - linked the acoustic form to the concept "tortoise". As a result of a metonymic transfer, the proper name was used as a generic noun. The acquisition of secondary, derived meanings depends, 
it seems, on the level of development of the human conceptual system and sufficient background knowledge. Consequently, language behavior in adults is different from that in children.

Indeed, adult speakers and children acquire the meanings of polysemous words differently. Adult speakers can acquire new meanings, both primary and secondary, after fewer presentations, since their conceptual system is fully established. Adult speech is dominated by verbs having a high degree of polysemy; the number of polysemous words in adult speech is much higher than that of children. Children, especially at the early stages of development, opt for nouns having fewer meanings. They want to have a name for everything in their external environment: "What is the name of the space between the bits that stick out on a comb?" (http://www.mama.com.au/14-questions-kids-ask). This is a conscious attempt at nomination.

Even though the following passage is an example of homonymy, it still demonstrates the tendency of children to use a separate word for each signified. The example below shows the urge of the child to have a separate word that can express his idea, his concept of gender differences: "We bought a water mister for our backyard. My son asked, "What do you call it if it's a girl?" (https://www.buzzfeed. com). This is an example of an erroneous categorization and attribution of human gender differences to an inanimate object ("mister - a form of address, a title" and "mister - a bottle with a nozzle for spraying a mist of water, as onto houseplants" (Collins Co-Build Dictionary). Children prefer less ambiguous words, thereby avoiding uncertainty.

Unlike adults, children reject attempts to use the same word in different meanings and prefer to use the words that are well known to them. They seek to comply with the law of the symmetry of the linguistic sign, so the same word should not be used to name different objects or artefacts.

We hold that during the acquisition of a new meaning of a polysemous word, there might be a conflict between the primary and secondary meanings: "Evie, aged seven, after a drug-awareness program at school: 'Mum, how do you smoke a pot? Do you stick your head in it? What are they breathing in? Won't the steam burn you if the stove is on?' " (a pot - "a deep round container used for cooking stews, soups, and other food" and pot - "sometimes used to refer to the drugs cannabis and marijuana", Collins Co-Build Dictionary) (http://www.mama.com. au/14-questions-kids-ask).

The conflict between the primary and secondary meanings of a polysemous word seems to be less apparent in adults than in children. So far we have failed to find convincing examples proving this argument.

We suggest that conceptual operations underlying secondary and further meaning acquisition develop according to the following algorithm:

- visual or acoustic input to the echoic or iconic memory;

- activation of the primary (basic) meaning;

- conflict between the basic and the new meanings;

- assessment of sufficiency/poverty of the stimulus;

- formation of a new concept; 
- linking the concept to the acoustic form;

- establishing a connection between primary and secondary meanings through individual invited inferencing;

- storing the meanings in the lexicon.

Our analysis has shown that the sequence of conceptual operations presented above, accompanying the acquisition of primary and secondary meanings, is conditional upon the time and character of cognitive operations. It is still unclear how these operations occur: do they occur consecutively or do some of them develop simultaneously? The nature of these cognitive operations requires further research involving neurologists and neurolinguists.

The opposite process - identification of the meaning of polysemous words depends on the cognitive context in which the new meaning is acquired and identified. Each polysemous word is associated with a set of dynamic cognitive contexts forming a complex multi-dimensional mental representation, which could potentially capture and store a significant amount of conceptual information, referring in fact to any number of conceptual domains that are relevant to the identification of a particular sense of the word (Zabotkina \& Boyarskaya, 2012; Zabotkina \& Boyarskaya 2013). Consider the following example:

"After telling my five-year-old daughter I'm excited because my favorite band is coming to town to play, she ran to her room and started cleaning up her toys. When I asked her what she was doing she said, 'Mommy, those are big guys and if they're coming over to play I do not want them stepping on my stuff. They'll break everything!'” (https://www.buzzfeed.com).

This example is revealing for several reasons: it is an illustration of a basic assumption that the primary meaning is preferred to the derived one (in this case "to play" - "spend time doing enjoyable things, such as using toys and taking part in games". The context of the situation serves as a prime for the activation of the basic meaning. Conceptual priming is a faster means of identifying a particular word meaning after the presentation of a prime. The results of our research show that a set of cognitive contexts (or a particular cognitive context) can act as a conceptual prime, leading to faster and more accurate identification of the target word sense. The method of probabilistic conceptual modelling of word sense disambiguation, which we suggest, clearly demonstrates the role of a particular type of cognitive context and conceptual primes in word sense disambiguation (ibid).

The mental lexicon performs an important role in polysemy resolution, since it is the mental lexicon that concentrates various types of cognitive processes connected with perception, processing, storage, retrieval, usage, and generation of knowledge. It is often understood as a system of concepts and links between them which have been formed as a result of human cognitive activity. The meanings and concepts they are based on form networks with other meanings related to them conceptually and, therefore, semantically. New meanings are not acquired in isolation. They integrate into existing conceptual networks. The more meanings are acquired, the more differentiated they are compared to other words and other meanings within the structure of the polysemous word. In the mental lexicon, a polysemous word may be represented by a complex mental representation - a set of cognitive contexts associated with different senses of the polysemous word. This 
mental representation may store a large volume of information belonging to different conceptual domains. This perspective is important in understanding what the meaning of a polysemous word is.

\section{Conclusion}

We have attempted to show the importance of an integrated approach to the challenge of polysemy. Such a novel approach is based on integrated knowledge emerging from the interaction of three disciplines of cognitive science - cognitive linguistics, cognitive psychology, and philosophy. It has been demonstrated that progress in the study of polysemy does not come from linguistics alone, but requires drawing on tools and methods from other cognitive paradigm disciplines. This allowed us to arrive at an interpretative hypothesis concerning the cognitive basis of meaning, analyzed within the dichotomy of the conscious versus the unconscious. This research has demonstrated that meanings are unconscious till a connection between the phonological, acoustic form and the concept is established. However, the acquisition of meaning is a conscious process; it is a conscious interaction of the speaker with another interlocutor and with the external environment. Polysemy as a multiplicity of meanings associated with one acoustic form is unconscious for the speaker or the listener provided they are native speakers. Polysemy is conscious during intentional activation of two or more meanings associated with an acoustic or visual form in puns or zeugmas.

We opted for the interaction-based approach, complementary to the braincentered computational one, and suggested algorithms of cognitive processes of the primary and secondary meaning acquisition by children and adults. The acquisition of secondary meanings inevitably results in a conflict between the primary meaning and the derived one. Further research into polysemy should be based on a range of new types of evidence obtained by neurologists and neurolinguists.

\section{Acknowledgements}

This study was supported by the Russian Science Foundation, RScF grant 17-7830029 .

\section{References}

Casas, B., Català, N., Ferrer-i-Cancho, R. \& Baixeries, J. (2014). The evolution of polysemy in child language. In E. A. Cartmill, S. Roberts, H. Lyn \& H. Cornish (Eds), Proceedings of the 10th International Conference on Evolution of Language. (pp. 409-410). Vienna, Austria, 14-17 April 2014. doi: 10.1142/9789814603638_0068

Gibbs, R. (2006). Why cognitive linguists should care more about empirical methods. In M. Gonzalez-Marquez, I. Mittelberg, S. Couson \& M. Spivey (Eds.), Methods in cognitive linguistics (pp. 2-16). Amsterdam, Philadelphia: John Benjamins.

Jackendoff, R.A. (2012). User's guide to thought and meaning. New York: Oxford University Press.

Huth, A., de Heer, W.A., Griffiths, T.L., Theunissen, F.E. \& Gallant, J.L. (2016). Natural speech reveals the semantic maps that tile human cerebral cortex. Nature, 532, 453-458. doi:10.1038/ nature17637 
Murray, G.K., Jones, P.B., Kuh, D., \& Richards, M. (2007). Infant developmental milestones and subsequent cognitive function. Annual Review of Neurology, 62, 128-136. doi: 0.1002/ ana. 21120

Mandelshtam, O. (1920). Swallow. Retrieved from http://max.mmlc.northwestern.edu/mdenner/ Demo/texts/swallow.html

Odoevskij, V.F. (1975). Psihologicheskie zametki [Psychological notes]. Moscow: Nauka.

Pinker, S. (2008). The stuff of thought: Language as a window into human nature. London: Penguin Books.

Pustejovsky, J., \& Bouillion, P. (1996). Lexical semantics in context. Oxford: Clarendon Press.

Tsvetayeva, M. (1924). Pismo Chernovoj A.V. Retrieved from http://www.tsvetayeva.com/letters/let_chern

Vygotsky, L.S. (1934/1987). Thinking and speech. In R. W. Rieber \& A. S. Carton (Eds.), The collected works of L. S. Vygotsky (Vol. 1, pp. 37-285). New York: Plenum.

Wittgenstein, L. (2016). Tractatus Logico-Philosophicus. Side-by-Side-By-Side Edition, version 0.44. Retrieved from https://people.umass.edu/klement/tlp/tlp.pdf

Zabotkina, V. (2016). Knowledge, reality, and interdisciplinary discourse. In The 3rd International Multidisciplinary Scientific Conference on Social Sciences and Arts SGEM2016 Conference Proceedings, Book 3 (Vol.1, pp. 587-594). Albena, Bulgaria, 06-09 April 2016.

Zabotkina, V.I., \& Boyarskaya, E.L. (2012). Cognitive modeling of sense disambiguation in polysemous words. Journal of International Scientific Publications: Language, Individual and Society, 6, 254-265.

Zabotkina, V.I., \& Boyarskaya, E.L. (2013). Sense disambiguation in polysemous words: Cognitive perspective. Psychology in Russia: State of the Art, 6(3), 60-67. doi: 10.11621/pir.2013.0306

Original manuscript received August 25, 2017

Revised manuscript accepted September 11, 2017

First published online September 30, 2017 